\title{
Do we Plan through Gestures? Evidence from Children, Adolescents and Adults in Solving of Tower of Hanoï Task ${ }^{*}$
}

¿Planeamos a través de los gestos? Evidencia en niños, adolescentes y adultos en la resolución de la tarea de la Torre de Hanoï

Received: 16 November 2015 | Accepted: 23 June 2017

\author{
MAYilín MOREnO \\ Universidad del Norte, Colombia \\ ORCID: http://orcid.org/0000-0002-4072-5087 \\ MichÈLE GuidetTI \\ Université de Toulouse Jean Jaurès, Francia
}

\begin{tabular}{lrl}
\hline${ }^{a}$ Correspondence & author. & E-mail: \\
mamoreno@uninorte.edu.co &
\end{tabular}

How to cite: Moreno, M., \& Guidetti, M. (2018). Do we Plan through Gestures? Evidence from Children, Adolescents and Adults in Solving of Tower of Hanoï Task. Universitas Psychologica, 17(2), 1-13. https://doi.org/10.11144/Javeriana.upsy17-2.pgec

\begin{abstract}
The aim of this research was to study the planning of the execution of the Tower of Hanoï task (TOH) through gesture and speech. The effects of age and task complexity on gestures-speech mismatches were analyzed in 144 participants ( 48 children from 8 to 10 years old, 48 adolescents from 12 to 14 years old, and 48 adults from 18 to 20 years old) during their early explanations of the solution to the problem of the TOH. Results suggested effects from task complexity but not from age. Gesture-speech mismatches could be a possible way to analyze early explanations of the tasks, and the level of difficulty could be considered as a developmental indicator. The question of the relationship between gestures and speech during the planning of complex problems is in fact at the center of a passionate debate on the close relationship between thought and language. It is also at the heart of research on multimodal communication and thinking, according to which human cognition is based on verbal and nonverbal aspects of communicative behavior.
\end{abstract}

Keywords

planning; Tower of Hanoi Task; gestures-speech mismatches; multimodal development.

\section{RESUMEN}

El objetivo de esta investigación fue estudiar la planificación de la ejecución de la tarea de la Torre de Hanoi $(\mathrm{TOH})$ a través de los gestos y la palabra. Se analizaron los efectos de la edad y la complejidad de la tarea en las discordancias gestos-palabras en 144 participantes (48 niños de 8 a 10 años, 48 adolescentes de 12 a 14 años y 48 adultos de 18 a 20 años) durante sus explicaciones anticipadas a la resolución de $\mathrm{TOH}$. Los resultados sugieren efectos de la complejidad de la tarea, pero no de la edad. Las discordancias gestos-palabras podrían constituirse en una manera posible de analizar explicaciones anticipadas a la resolución efectiva de las tareas, y el nivel de dificultad podría ser considerado como un indicador de desarrollo. La pregunta de la relación entre los gestos y las palabras durante la planificación de problemas complejos es, de hecho, el centro de un apasionado debate sobre la estrecha relación entre pensamiento y lenguaje. También está en el centro de la investigación sobre la comunicación y el pensamiento multimodales, según la cual la 
cognición humana se basa en los aspectos verbales y no verbales del comportamiento comunicativo.

Palabras clave

planificación; Tarea de la Torre de Hanoï; discordancias gestospalabras; desarrollo multimodal.

Research done over the last years suggests that studying co-speech gestures could be very useful for understanding the relationship between language and thought (Goldin-Meadow \& Alibali, 2013; McNeill, 2005). Gestures can change the mental representations of the speakers (Beilock \& Goldin-Meadow, 2010) and can even influence the way we think. Gestures not only reflect the thought of the one who produces it, but can offer a feedback to the thought (Goldin-Meadow \& Beilock, 2010). Gestures are actions, but at the same time, they represent information. In sum, they play an important role, as they add information to the mental representation and show concrete actions as abstract ideas (Goldin-Meadow, 2015). However, why do people make gestures while speaking? Why do people talk with their hands? Do these hand movements have any special significance or not?

Since the late 80's, Susan Goldin-Meadow and colleagues have also shown that cospeech gestures play a role in facilitating the development of knowledge and indicate a state of transition towards this new knowledge. According to them, when solving a variety of problems, children and adults make gestures that contain different and complementary information from the one conveyed by speech. They call this phenomenon gesture-speech mismatch (Alibali \& Goldin-Meadow, 1993; Church \& Goldin-Meadow, 1986; GoldinMeadow, 2011; Perry, Church, \& GoldinMeadow, 1988; Perry \& Elder, 1997). The simultaneous activation of multiple ideas or strategies about the solution of a problem characterizes this state of transition of knowledge and is the cause of this gestures-speech mismatch. In fact, what happens is that gesture and speech convey two different ideas about the same problem: gesture conveys one idea, speech conveys another.

This is what Garber (1997) and Garber and Goldin-Meadow (2002) found in their research about the solution of the Tower of Hanoï problem. This is a puzzle in which a graduated tower of disks must be moved from a source peg to a goal peg. The largest disk is found on the bottom and the smallest on the top. There are two rules (Egan \& Greeno, 1973): firstly, only one disk may be moved at a time and secondly, a larger disk must not be placed on top of a smaller one. The most efficient solution to the problem is made by repeating comparisons of the current state of the disk to intermediate and final goal states (Newell \& Simon, 1972).

They found that when explaining the solution to the Tower of Hanoï problem $(\mathrm{TOH})$, gesturespeech mismatches indicate that the problemsolver has in mind two different strategies for accomplishing this task: the first considered consciously through speech, the second less consciously through gesture. From here, they formulated the hypotheses that participants would produce more gesture-speech mismatches when explaining key moments or choice points of the solution to the problem (and not in other moments). This would indicate that at these choice points, participants must make a choice between two different possible strategies for an optimal solution of the task. These choice points, predetermined by the problem, become decision moments where the participant must carefully analyze their next decision in moving a disk. In other words, at those choice points participants have two ways: one that leads to solve the problem in the fewest number of moves (optimal solution), and another one in more moves (nonoptimal solution).

Garber (1997) and Garber and GoldinMeadow (2002) found other results which show that participants (children and adults) produced more gesture-speech mismatches at those choice points. This suggests that gesturesspeech mismatches could be a "good" indicator of planning for the solution of the $\mathrm{TOH}$ problem. This is demonstrated by the fact that gesturespeech mismatches happen just at those choice 
points where participants have to make a choice between two different strategies and, to do so, they have to anticipate the resolution of the problem. They also found a link between the level of complexity of the task (represented by the number of disk) and the high production of gestures-speech mismatches. However, they did not find significant differences in the number of mismatches produced by participants; i.e. children and adults produced mismatches in equal proportion.

In the context of the findings of these researchers, two issues aroused our interest. The first one was the relationship between gesturesspeech mismatches and planning, suggested by Garber (1997) and Garber and Goldin-Meadow (2002). The second one was their finding that there was no significant difference in the number of mismatches produced by children and adults.

On the other hand, planning has been studied from different theoretical approaches: behaviorist (Berger, Guilford, \& Christensen, 1957; Miller, Galanter, \& Pribram, 1960; Mumford, Schultz, \& Van Doorn, 2001; Osburn \& Mumford, 2006); cognitivist (Anderson, 1993; Newell \& Simon, 1972; Reed, 1999; Richard, 1982, 1988, 1997, 2004; Rönnlund, Lövdén, \& Lars-Göran, 2001); and finally, neuropsychological. Under this last approach, planning is part of the executive functions, executive control, or cognitive control (Anderson, 1998; Aran, 2011; Barceló, Lewis, \& Moreno, 2006; Barroso-Martin \& Leon-Carrion, 2002; Blaye \& Chevalier, 2014; Chevalier, 2010; De Luca et al., 2003; Díaz et al., 2012; Diamond, 2013; Hughes \& Graham, 2002; Lezak, 1995; Miyake et al., 2000). According to Diamond (2013), executive functions "refer to a family of top-down mental processes needed when you have to concentrate and pay attention, when going on automatic or relying on instinct or intuition would be ill-advised, insufficient, or impossible" (p. 136). She classifies planning (along with reasoning and problems solution) as a higher-order executive function. Therefore, this approach considers planning as anticipation of a sequence of different actions before they are implemented.
Richard (1982) claims that the TOH task is one of the most adequate problems of transformation of states for studying planning. The reason for this is that setting intermediate targets and searching for the required conditions for their accomplishment are critical stages in the process of solution of the task. Other studies come to the same conclusion (Anderson \& Douglas, 2001; Aran, 2011; Byrnes \& Spitz, 1979; De Luca et al., 2003; Díaz et al., 2012; Welsh, 1991). According to this research, it seems that the planning capacity needed for these types of tasks is rare before the age of seven and would only be possible by the age of eight. The literature shows that there is a fast development of this planning capacity between the ages of eight and nine, then a plateau moment between the ages of 9 and 12, followed by an important development between the ages of 12 and 14 and finally a plateau again (Blaye \& Chevalier, 2014; Byrnes \& Spitz, 1979; Chevalier, 2010; De Luca et al., 2003; Richard, 1982; Welsh, Penington, \& Groisser, 1991).

More recent studies have used the $\mathrm{TOH}$ task in order to explore the relationship between gestures and problem solving. They try to demonstrate that gestures are not simple reproductions of actions already carried out (explaining the $\mathrm{TOH}$ task after having moved the disks) but that they are complex representations of problem solving (Beilock \& Goldin-Meadow, 2010; Cook \& Tanenhaus, 2009; Goldin-Meadow \& Beilock; 2010; Trofatter, Kontra, Beilock, \& Goldin-Meadow, 2015). Nevertheless, none of these studies has related the production of gesture-speech mismatches to planning through the resolution of this $\mathrm{TOH}$ problem.

As mentioned above, Garber (1997) and Garber and Goldin-Meadow (2002) used the $\mathrm{TOH}$ to analyze the gesture-speech mismatches produced by children and adults during the explanation of the solution of the $\mathrm{TOH}$ puzzle after they had done it. Our interest in the process of planning led us to focus on the role of gesturespeech mismatches in planning. That is why in our work the aim was to study the gesturespeech mismatches produced by children and 
adults while they explained the resolution of the $\mathrm{TOH}$ before they implemented it. We explored this through different ages chosen according to previous studies on the development of planning and according to the levels of complexity of the task ( 3 and 4 disk).

\section{Method}

\section{Participants}

Adults

Forty-eight college students $(M=19$ years; range $=18$ to 20 years), 24 males and 24 females, recruited from different colleges and enrolled in different schools (Engineering, Psychology, International Business, Medicine, Nursing, etc.) participated voluntarily and were interviewed after having signed the informed consent.

Adolescents

Forty-eight school pupils ( $\mathrm{M}=12$ years; range $=12$ to 14 years), 24 males and 24 females, were recruited from different schools. They participated in the task after obtaining informed consent from their parents.

Children

Forty-eight school pupils $(\mathrm{M}=9$ years; range $=8$ to 10 years), 24 males and 24 females, were recruited from different schools, they participated in the task after obtaining informed consent from the parents.

All the participants live in a region of the Colombian Caribbean coast. None of them received compensation for their participation. Three conditions were required to include participants in this study: a) not presenting scholarly or academic difficulties; b) not presenting psychological and/or visual difficulties which could prevent them from taking the test; and c) not knowing the $\mathrm{TOH}$ task. These conditions were verified by the school in the case of the adolescents and children or by the adult students themselves.

\section{Material and task}

Device

Our material was the $\mathrm{TOH}$ puzzle. It was composed of a wooden flat base which measured $20 \times 10 \mathrm{~cm}$, three vertical rods which measured 8 $\mathrm{cm}(\mathrm{A}, \mathrm{B}$, and $\mathrm{C})$, and wooden disks of different colors (yellow, red, green, and blue). The smallest disk measured $3 \mathrm{~cm}$ in diameter. The other disks were increasingly bigger. These disks were called according to their sizes: disk 1, 2, 3, and 4. Disk 1 was the smallest and disk 3 was the biggest in the task version with 3 disks; disk 1 was the smallest and disk 4 the biggest in the task version with 4 disks.

Rules

The task consisted of moving the disk from a starting tower $(\operatorname{Rod} A)$ to a finishing tower $(\operatorname{Rod} C)$ through an intermediate tower $(\operatorname{Rod} B)$, respecting the following rules: (1) move only one disk at a time; (2) do not hold a disk in the hand nor put them on the table (the disk should always be on any of the rods), and (3) never put a bigger disk on a smaller one (Piaget, 1974; Welsh, Satterlee-Cartmell, \& Stine, 1999). Figure 1 shows the space-problem diagram (Newell \& Simon, 1972) of the task with four disks. The minimum number of required moves to solve any version of the $\mathrm{TOH}$ task in an optimal way was $2^{\mathrm{n}}-1$; where $n=$ number of disk ( 7 moves for the three-disk task and 15 for the four-disk task). 
Figure 1

Diagram of the space-problem for the 4-disk task of the Tower of Hanoi puzzle. It represents all possible configurations and transfers of disk authorized by the game.

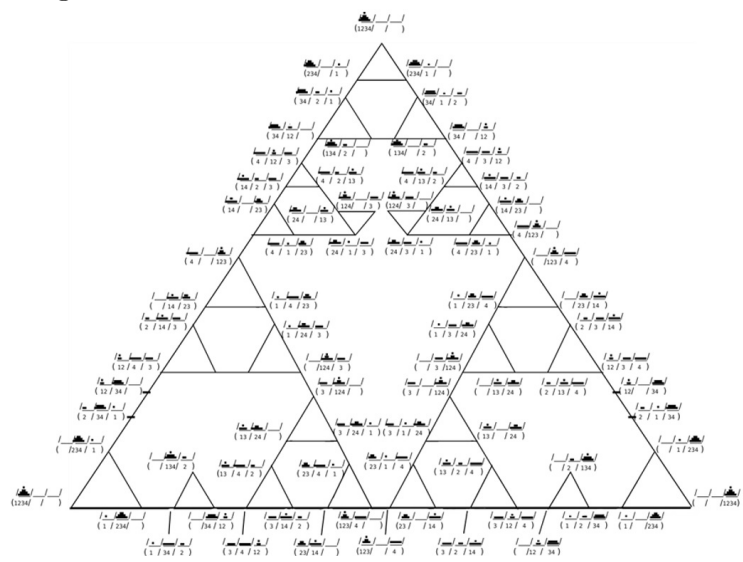

The numbers represent disk, 1 is the smallest disk, and 4 is the largest disk. The right side of the diagram represents the optimal resolution of the task in 15 movements. Movements 1, 5, 9 and 13 correspond to the choice points of the task

\section{Procedure}

\section{Training phase}

The training process began with two disks in the first rod. The experimenter explained the rules accompanying the explanation with hand gestures while pointing at the disk. After that, the experimenter asked participants to repeat the instructions and rules, and then, to explain how to solve the problem without moving the disk. Finally, the participant was asked to move the disk. After completion of the training task with two disks, the experimenter set the disk on the first rod and explained to participants that the game continues with the same procedure as in the task with two disks but this time a third disk and finally a fourth disk was added.

Development of the task

First, participants were invited to explain their task resolution without moving the disk, then asked to perform the task by moving disk. Here only the planning phase was analyzed rather than the movement of disk. The examples of Figures 2 and 3 illustrate, respectively, the explanation of the experimenter on the task with 3 disk (T3d) and early explanation of the participant performing the task with 3 disk (T3d):

Figure 2

Experimenter's instructions - T3d

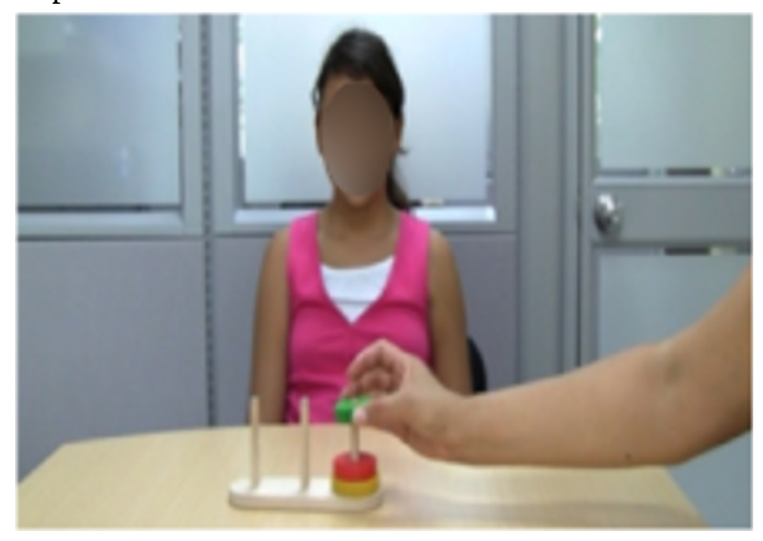

Figure 3

Explanation - T3d (Phase 1)

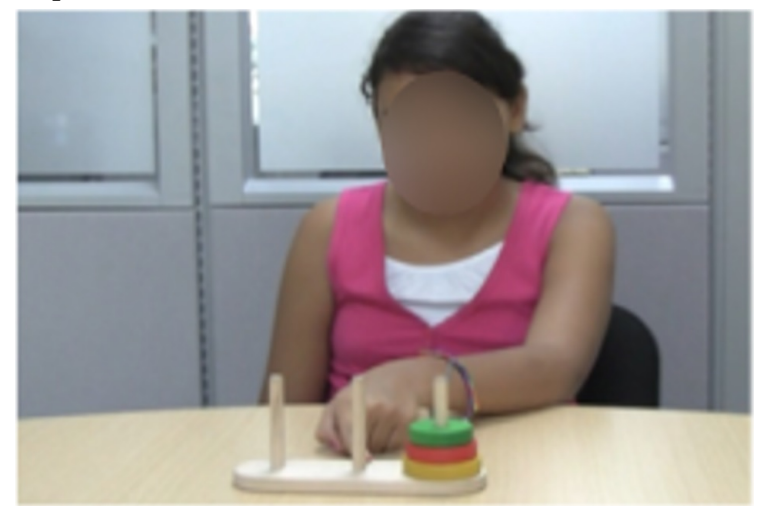

To explain each problem (with three, then four disk), a type of paradigm "controlled" by the learner was chosen, i.e., there was no time limitation or imposition of test explanations on the task (Clément \& Richard, 1997). However, after three unsuccessful attempts to explain the task, the difficulties of participants were considered and they were invited to perform the task. The maximum degree of complexity was measured by the four-disk task for all participants. At the end of every session, two questions were asked: "What do you think of the test?" and, "What strategies did you apply to solve the task?"

The planning phase was completed only when the participants had completed the task 
through their explanation, that is, when they had reconstructed the tower in their explanation (with three and four disk) in the same order as the last rod $(\operatorname{rod} \mathrm{C})$.

All participants were tested individually for a session of 15-20 minutes on average in an empty room made available by the school (meeting rooms, classrooms, library, conference room, music studio, or coordinating school office) in the case of children. With adults, sessions were held in a laboratory of psychology at the University. Both sessions with adults as with children were filmed entirely with the respective authorizations (following code of Ethics of Colombia).

\section{Coding}

144 footages were fully transcribed and coded according to the system described by Garber (1997), and Garber and Goldin-Meadow (2002).

Thus, a coder transcribed and coded first (a) the movement of disk described in speech, (b) the movement described in gestures, (c) the mismatches between gestures and speech, and d) the manual movement of disk. A gesture was defined as any movement of pointing gestures or iconic gestures representing the shape of the disk of one or two hands directed at the $\mathrm{TOH}$, indicating the displacement of a disk from one rod to another. Private gestures or other hand movements, such as touching or taking a disk, scratching the head, touching the face, etc., were not considered a part of gestures associated with the path of a disk, and therefore, they were not coded (Ekman \& Friesen, 1969; Garber \& Goldin-Meadow, 2002). In this phase, the coding process aimed to: 1) determine the number of movements of "mental" disk arising from verbal explanations and gestural explanations to solve the task with three disk (3d) and four disk (4d). This allowed for the identification of the type of strategy used by participants. The strategy was optimal when the participant (through explanations of the verbal and gestural trajectory ${ }^{1}$ ) solved the task in the lowest number of movements ( 7 for the task with $3 \mathrm{~d}$ and 15 for the task with $4 \mathrm{~d}$ ); and it was non-optimal, when the participant solved the task in a larger number of movements $(+7$ and $+/-15$ for tasks with $3 \mathrm{~d}$ and $4 \mathrm{~d}$, respectively).
When the participants did a lower number of movements but which did not reach an optimal planning, i.e. they did not perform and end the task as expected, these were also considered as non-optimal strategies. For this, different trajectories of movements authorized in diagrams of the problem space (Newell \& Simon, 1972) of the $\mathrm{TOH}$ were relied on. The second step was 2) to identify (for each movement and each verbal and gestural trajectory), the match and mismatch relationship between gestures and speech. Matches and mismatches were defined as stated in the article of Garber (1997) and Garber and Goldin-Meadow (2002), Figures 4 and 5 present examples of gestures-speech match and mismatches.

When explaining the task with three disks, a girl (Figure 4) described her first movement of the green disk from rod A to rod C, by saying: "I would take this [the green disk on rod A] and I would place it here $[\operatorname{rod} C] "$. At the same time, she accompanied her explanation by illustrating her verbal message and indicating with her gesture the rod A with her left hand, and the rod $\mathrm{C}$ with her right hand. In this case, both verbalization of movement 1 and her gesture referred to the same disk and the same rod. This was a typical case of match between the explanation of the first movement indicated verbally and the explanation of the non-verbal movement, indicated with gestures.

In contrast, Figure 5 illustrates one of the three cases of mismatch (Garber \& GoldinMeadow, 2002). The gesture transmitted a different trajectory that was not identified in the speech. For example, in the three-disk task, the participant described the first movement of the green disk from the first rod to the third rod, by saying: "I move the green disk to a rod" (the participant did not specify which rod), and then the participant said, "the rod C", while pointing with a gesture the $\operatorname{rod} \mathrm{B}$, the rod of the middle. 
Figure 4

Gesture-speech match

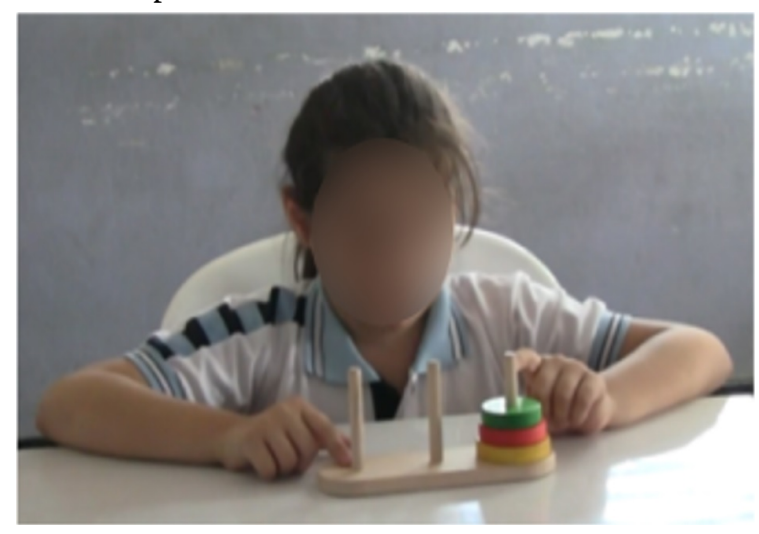

Figure 5

Gesture-speech mismatch

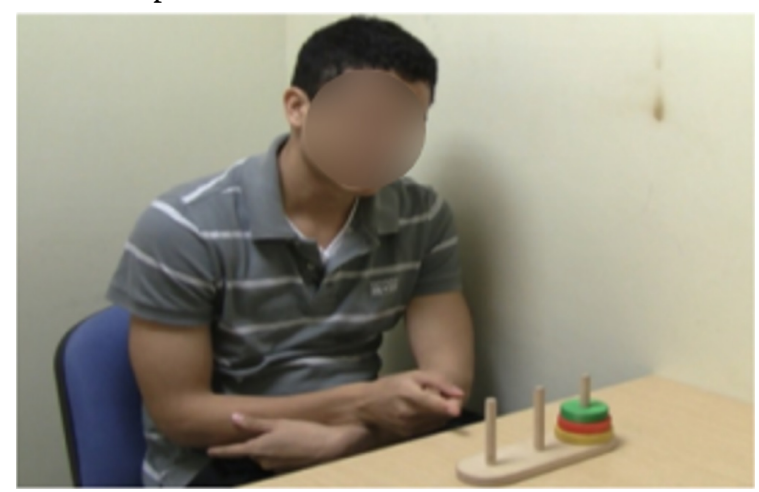

In this phase, several attempts at explanation (verbal and gestural) were generated by participants prior to their final explanation. The last attempt to explain the tasks was coded and analyzed. However, the number of attempts produced by participants before the final attempt was recorded as the final attempt was not necessarily the one that led to the optimal resolution of the task. Finally, the explanation time in seconds i.e. the time between the end of the instruction given by the experimenter and the end of the last attempt at explanation by the participant was registered.

\section{Reliability}

A double coding was performed on 12.5 $\%$ of data (18 participants: 6 children, 6 adolescents and 6 adults). Reliability was established through a second evaluator who transcribed and encoded separately the following variables: average speech movements (NDV), average gestural movements (NDG), average gestures-speech matches/mismatches (MM) of the task of the $\mathrm{TOH}$ with $3 \mathrm{~d}$ and $4 \mathrm{~d}$. This allowed us to determine a correlation coefficient between two evaluators: Kappa Cohen. Interrater agreement was determined by calculating the agreement proportion between the two encoders and the coefficient of Cohen's Kappa $(K)$. In the 3-disk task, for adults, adolescents, and children agreement between coders was 1 for describing moves in speech (kappa = 1); 1 for describing moves in gesture (1), and 1 for describing gesture-speech matches and mismatches (1). In the 4-disk task, for adults, agreement between coders was 1 for describing moves in speech (kappa $=1)$; 1 for describing moves in gesture (1), and 1 for describing gesture-speech matches and mismatches (1). For adolescents, comparable numbers were: 77 (1); 77 (0.94); 77 (0.88). and for children, comparable numbers were: 80 (1); 80 (0.94); 80 (0.88).

The following hypotheses were posed:

1. An effect of age on mismatches depending on the type of strategy (optimal and non-optimal) was expected. The hypothesis that the older the age, the larger the number of optimal resolutions of the task, associated with a high frequency of "mismatches" was formulated. This would indicate the ability of participants to anticipate (both for gestures and speech) the chances of resolving the $\mathrm{TOH}$.

2. Task complexity was expected to affect mismatches. It was expected here that the complexity of the task $(\mathrm{TOH})$ had an effect on the production of gesturesspeech mismatches in participant's explanations when planning the $\mathrm{TOH}$ with 3 and 4 disks.

\section{Results}

An effect of age on mismatches depending on the type of strategy (optimal and non-optimal) was expected. The hypothesis that the older the age, the larger the number of optimal resolutions 
of the task, associated with a high frequency of "mismatches" was formulated. This would indicate the ability of participants to anticipate (both for gestures and speech) the chances of resolving the $\mathrm{TOH}$.

Is there any effect of the age on production of mismatches?

We considered the number of gestures-speech mismatches produced by participants during their verbal and gestural explanations (according to the classification of Garber,1997 and Garber and Goldin-Meadow, 2002), and we wondered whether there was an effect of age on the production of these mismatches for the types of planning strategies of participants. A twofactor ANOVA with age as a between-subjects factor and type of planning strategy (optimal or non-optimal) as a within-subject factor was performed. The total number of mismatches was taken as a dependent variable. We found no effect of age on the production of gestures-speech mismatches considering the type of planning strategy in the task of 3 disks $(F(2,115)=0.957$; $p>0.387)$, nor in the task with 4 disks $F(2,117)$ $=0.049 ; p>0.952)$. However, the analysis of variance showed a simple effect of type of strategy on production of gestures-speech mismatch in the task with 3 disks $(F(1,115)=17.559, p<0)$ as it is shown in Figure 6, but not in task with 4 disks $(F(1,117)=0.052 ; p>0.82)$.

\section{Figure 6}

Mean and standard deviation of gestures speech mismatches according to type of strategy used in the task with three disks

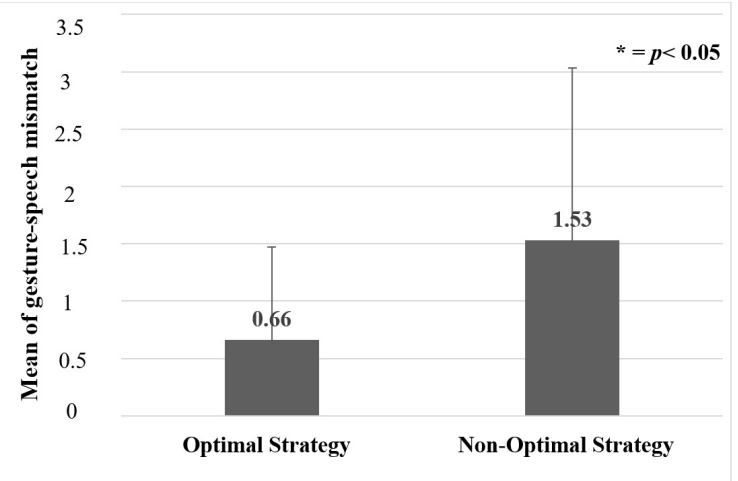

Is there any effect of the complexity of the task on production of mismatches?

We expected here that the complexity of the $\mathrm{TOH}$ task would have an effect on the production of gestures-speech mismatches in participant's explanations when planning the solution of the $\mathrm{TOH}$ with three and four disks. The analysis revealed a simple effect of the task complexity on the number of mismatches $(F(1$, $121)=14.501, p<0)$. The mean of gesturespeech mismatches was higher in four disk $\mathrm{TOH}$ planning than the one in three disks. Therefore, we confirm this hypothesis (cf. Figure 7).

Figure 7

Mean of mismatches between gestures and speech depending on the complexity of the task: three and four disks

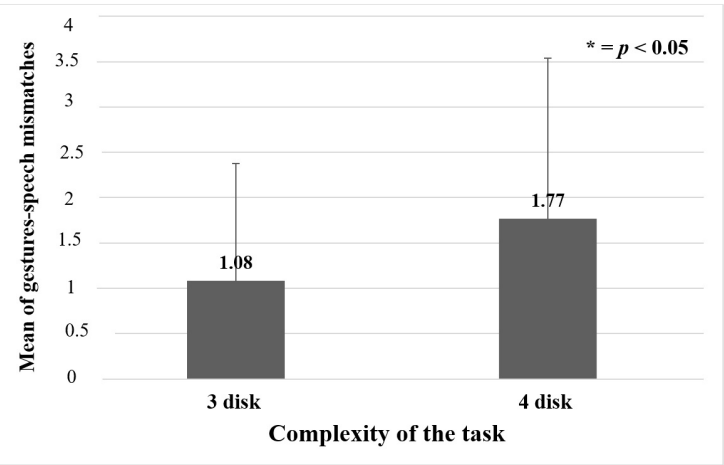

To test this hypothesis in terms of age, an analysis of variance for repeated measures was performed. All subjects (8-10 years old children, 12-14 years old teenagers, and $18-20$ years old adults) overcame the problem conditions with three and four disks. Our dependent variable was the average of gestures-speech mismatches, our within-subject variable, the complexity of the task, and our between-subjects variable, age. However, the analysis did not reveal any effect of the complexity of the task on the number of mismatches associated with age $(F(2,121)=$ 0.693; $p>0.502$ ).

\section{Discussion}

This research focused on the role of gestures and particularly, the role of gestures-speech 
mismatches in the planning of the $\mathrm{TOH}$ task. In their research, Garber (1997) and Garber and Goldin-Meadow (2002) found that participants (children and adults) produced more gesturespeech mismatches at choice points while solving the task. This suggested that gestures-speech mismatches could be a "good" indicator of planning for the solution of the $\mathrm{TOH}$ problem. This was demonstrated by the fact that gesturespeech mismatches happen just at those choice points where participants have to make a choice between two different strategies and to do so they have to anticipate the resolution of the problem. They also found a link between the level of complexity of the task (represented by the number of disks) and the production of gestures-speech mismatches. However, they did not find significant differences in the number of mismatches produced by different kind of participants; i.e. children and adults produced mismatches in equal proportion.

From these findings, we conducted our research, assuming that just like the classic studies on the resolution and planning of the $\mathrm{TOH}$ problem, we could confirm the effects of age and complexity of the planning task through the study of gestures-speech mismatches. Our interest in the process of planning led us to focus on the role in planning of gesture-speech mismatches. That is why in our work the aim was to study the gesture-speech mismatches produced by children and adults while they explained the resolution of the $\mathrm{TOH}$ before they implemented it. We explored this through different ages chosen according to previous studies on the development of planning and according to the levels of complexity of the task (three and four disks).

According to this goal, we formed three age groups and presented the task with two levels of complexity. To date, no research (to our knowledge) had studied planning by using gestures-speech mismatches from a developmental perspective. Our research sought to fill this gap. We consider that the originality of our research consisted just in trying to find another way to study planning. We think that this complex process cannot be demonstrated only through the results of the solution of a task such as the $\mathrm{TOH}$. Nevertheless, although our results did not led to totally confirm our hypotheses, they let to falsify some of them.

We confirmed, as other investigations did, that all participants produced mostly gestures to explain their $\mathrm{TOH}$ solution. This shows that gestures can also be studied in advance during planning of problem solving tasks and not just during explanations subsequent to its execution. In other words, we confirmed the power of gesture for explaining complex cognitive tasks. This has been demonstrated by recent studies (Alibali et al., 2014; Alibali, Church, Kita, Sotaro, \& Hostetter, 2014; Chu \& Kita, 2016; Kita, Alibali, \& Chu, 2017). However, we did not find, as we expected, any relationship between planning development and production of mismatches at the choice points. Our participants, regardless of the age, did not produce significant number of mismatches at the choice points while using optimal strategies for solving the TOH task. Many of them could solve the three-disk task using an optimal strategy without producing any mismatch. This was not the case for the four-disk task. For this task, they produced more gesture-speech mismatches but age made no difference while complexity of the task did. This suggests that the three disks task is probably solved by participants automatically, without any cognitive control or planning. This could explain why they did not produce any gesture-speech mismatches. On the other hand, the four disks task, given its complexity, requires more cognitive organization and planning. In fact, we found significant differences concerning the production of gesture-speech mismatches when considering the complexity of the task.

Now, we might wonder if the fact that participants did not produce gestures-speech mismatches at the choice points is a sign of non-planning or if mismatches are not a good indicator of planning. At this point in the discussion and trying to answer these questions, it is important to explain that planning is related to other cognitive functions that we did not considered in this research: working memory and inhibition. According to Monette 
and Bigras (2008), planning is closely linked to these two cognitive functions since working memory is required in order to make a plan through the development of sub-vocalizations or mental images. Inhibition, on the other hand, is necessary because participants must often inhibit a dominant behavior in order to plan. Future studies on planning using mismatches, should take into account these cognitive functions to make a deeper analysis of the development of planning. What we suggest here is that a single indicator is not enough for evaluating planning.

Another explanation for the nonconfirmation of our hypothesis of the relationship between the production of gestures-speech mismatches and the development of planning could be the protocol we followed in our research. Contrary to the one used by Garber (1997) and Garber and Goldin-Meadow (2002), and since we were interested in planning, we asked our participants to explain the task before moving the discs; a request that demanded from them an enormous capacity for abstraction. More recent studies with the $\mathrm{TOH}$ task and related to gestures have demonstrated, for example, that when confronted to two different situations, one using an actual $\mathrm{TOH}$ and the other a digital one, participants produced more gestures when solving the task with the actual $\mathrm{TOH}$ (Cook \& Tanenhaus, 2009). In the case of the protocol used by Garber and GoldinMeadow (2002), the fact that participants have had a real experience with the disks before explaining their resolution could favor the production of mismatches, therefore, the planning of the task. These interpretations remain limited because we do not have other studies about the relationship between gesturesspeech mismatches and planning. Recently, studies have been developed with the $\mathrm{TOH}$ task and related to gestures, but not to the production of mismatches (Beilock \& GoldinMeadow, 2010; Cook \& Tanenhaus, 2009; Goldin-Meadow \& Beilock, 2010; Trofatter et al., 2014).

Nonetheless, because of the reasons we just explained, gestures-speech mismatches may not be a sufficient indicator for explaining the anticipated representation of the resolution of the task before moving the disks. However, they could predict the subsequent optimal resolution of the task; i.e. subsequent planning. We are currently analyzing our data to test whether participants who produced more mismatches before actually solving the task by moving the discs, had an effective subsequent planning. This would be a great step forward because we could thus talk about development and learning of planning through gestures. According to Novack $\&$ Goldin-Meadow (2017), because gestures are abstract representations and are not actions linked to events and particular objects, they can play a powerful role in thinking and learning beyond the particular, specifically in support of generalization and transfer of knowledge.

\section{References}

Alibali, M. W., \& Goldin-Meadow, S. (1993). Transitions in learning: What the hands reveal about a child's state of mind. Cognitive Psychology, 25, 468-523.

Alibali, M. W., Nathan, M. J., Wolfgram, M. S., Church, B. R., Jacobs, S. A., Johnson, C., \& Knuth, E. J. (2014). How Teachers Link Ideas in Mathematics Instruction Using Speech and Gesture: A Corpus Analysis. Cognition and Instruction, 32 (1), 65-100.

Alibali, M. W., Church, R. B., Kita, S., \& Hostetter, A. B. (2014). Embodied knowledge in the development of conservation of quantity: evidence from gesture. In L. Edwards, F. Ferrara, \& D. Moore-Russo (Eds.), Emerging perspectives on gesture and embodiment in mathematics. Cognition, Equity $\mathcal{E}$ Society: International Perspectives (pp. 27-49). Charlotte, NC: Information Age Press.

Anderson, J. R. (1993). Problem Solving and Learning. American Psychologist, 48(1), $35-44$.

Anderson, V. A. (1998). Assessing executive functions in children: biological, psychological, and developmental 
considerations. Neuropsychological rehabilitation, 8(3), 319-49.

Anderson, J. R., \& Douglas, S. (2001). Tower of Hanoi: Evidence for the Cost of Goal Retrieval. Journal of Experimental Psychology: Learning, Memory, and Cognition, 27(6), 1331-1346.

Arán, V. (2011). Funciones ejecutivas en niños escolarizados: efectos de la edad y del estrato socioeconómico. Avances en Psicología Latinoamericana, 29(1), 98-113.

Barceló, E., Lewis, S., \& Moreno, M. (2006). Funciones ejecutivas en estudiantes universitarios que presentan alto y bajo rendimiento académico. Psicología desde el Caribe, 18, 109-138.

Barroso-Martin, J. M., \& León-Carrión, J. (2002). Funciones ejecutivas: control, planificación y organización del conocimiento. Revista de Psicología general y aplicada, 55(1), 27-44.

Blaye, A., \& Chevalier, N. (2014). Contrôle exécutif et développement. Psychologie française, 59(1), 1-3.

Beilock, S. L, \& Goldin-Meadow, S. (2010). Gestures changes thought by grounding it in action. Psychological Science, 21(11), 1605-1610.

Berger, R. M., Guilford. P., \& Christensen, P. R. (1957). A Factor-Analytic Study of Planning Abilities. Psychological Monographs: General and Applied, 71(6), $1-31$.

Byrnes, M. N., \& Spitz, H. H. (1979). Developmental progression of performance on the Tower of Hanoï problem. Bulletin of the Psychonomic Society, 14(5), 379-381.

Clément, E., \& Richard, J-F. (1997). Knowledge of domain effects in problem representation: the case of the Tower of Hanoi isomorphs. Thinking and Reasoning, $3(2), 133-157$.

Chevalier, N. (2010). Les fonctions exécutives chez l'enfant: concepts et développement. Canadian Psychology, 51 (3), 149-163.

Cook, S. W., \& Tanenhaus, M. K. (2009). Embodied communication: Speaker's gestures affect listeners' actions. Cognition, 113(1), 98-104.

Chu, M., \& Kita, S. (2016). Co-thought and co-speech gestures are generated by the same action generation process. Journal of Experimental Psychology: Learning Memory and Cognition, 42(2), 257-270.

Church, R. B., \& Goldin-Meadow, S. (1986). The mismatch between gesture and speech as an index of transitional knowledge. Cognition, 23(1), 43-71.

De Luca, C. R., Wood, S. J., Anderson, V., Buchanan, J. A., Proffitt, T. M., Mahony, K., $\&$ Pantelis, C. (2003). Normative data from the CANTAB: I. Development of executive function over the lifespan. Journal of Clinical and Experimental Neuropsychology, 25(2), 242-254.

Díaz, A., Martín, R., Jiménez, J. E., García, E., Hernández, S., \& Rodríguez, C. (2012). Torre de Hanoi: datos normativos y desarrollo evolutivo de la planificación. European Journal of Education and Psychology, 5(1), 79-91.

Diamond, A. (2013). Executive Functions. Annual Review of Psychology, 64, 135-68.

Egan, D. E., \& Greeno, J. G. (1973). Acquiring cognitive structure by discovery and rule learning. Journal of Educational Psychology, 64(1), 85-97.

Ekman., P, \& Friesen, W. V. (1969). The repertoire of non-verbal behavior: Categories, origins, usage and coding. Semiotica, 1(1), 49-98.

Garber, P. (1997). Using gesture and speech to index understanding of a problem solving task: A comparative study of adults and children explaining the Tower of Hanoi puzzle (Unpublished Ph.D. dissertation). Chicago: University of Chicago.

Garber, P., \& Goldin-Meadow, S. (2002). Gesture offers insight into problem-solving in adults and children. Cognitive Science, 26, 817-831.

Goldin-Meadow, S., \& Beilock, S. L. (2010). Action's influence on thought: The case of gesture. Perspectives on Psychological Science, 5(6), 664-674. 
Goldin-Meadow, S. (2011). Learning though gesture. Advanced Review, 2(6), 595-607.

Goldin-Meadow, S., \& Alibali. (2013). Gesture's role in speaking, learning, and creating language. Annual Review of Psychology, 64, 257-283.

Goldin-Meadow, S. (2015). From action to abstraction: Gesture as a mechanism of change. Developmental review, 38, 167-184.

Hugues, C., \& Graham, C. (2002). Measuring Executives Functions in Childhood: Problems and Solutions. Child and Adolescent Mental Health, 7(3), 131-142.

Kita, S., Alibali, M. W., \& Chu, M. (2017). How Do Gestures Influence Thinking and Speaking? The Gesture-for-Conceptualization Hypothesis. Psychological Review, 124(3), 245-266.

Lezak, M. D. (1995). Neuropsychological assessment. New York: Oxford University Press.

McNeill, D. (2005). Gestures and Thought. Chicago, IL: University of Chicago Press.

Miller, G. A., Galanter, E., \& Pribram, K.H. (1960). Plans and the Structure of Behavior. New York: Holt.

Miyake, A., Friedman P. N., Emerson, M. J., Witski, A. H., Howerter, A., \& Wager, T. (2000). The unity and diversity of executive functions and their contributions to complex 'frontal lobe' tasks: a latent variable analysis. Cognitive Psychology, $41(1), 49-100$.

Monette, S., \& Bigras, M. (2008). La mesure des fonctions exécutives chez les enfants d'âge préscolaire. Psychologie canadienne, 49(4), 323-341.

Mumford D. M., Schultz A.R., \& Van Doorn, R. J. (2001). Performance in Planning: Processes, Requirements, and Errors. Review of General Psychology, 5(3), 213-240.

Newell, A., \& Simon, H. A. (1972). Human problem solving. Englewood Cliffs, NJ: Prentice-Hall.

Novack, M., \& Goldin-Meadow, S. (2017). Gesture as representational action: A paper about function. Psychonomic Bulletin and Review, 24(3), 652-665.

Osburn., H. K \& Mumford, M. D. (2006). Creativity and Planning: Training Interventions to Develop Creative Problem-Solving Skills. Creativity Research Journal, 18(2), 173-190.

Perry, M., Church, R. B., \& Goldin-Meadow, S. (1988). Transitional knowledge in the acquisition of concepts. Cognitive Development, 3(4), 359-400.

Perry, M., \& Elder, A. D. (1997). Knowledge in transition: adults' developing understanding of a principle of physical causality. Cognitive Development, 12(1), 131-157.

Piaget, J. (1974). La prise de conscience. Paris: PUF. Reed, S. (1999). Cognition : théories et applications. Paris: De Boek.

Richard, J. F. (1982). Planification et organisation des actions dans la résolution du problème de la Tour de Hanoï par des enfants de 7 ans. L'année psychologique, 82 (2), 307-336.

Richard, J. F. (1988). Les activités de planification chez l'enfant. Revue française de pédagogie, 82(1), 33-37.

Richard, J. F. (1997). La résolution de problèmes. Recherche en soins infirmiers, 50, 47-54.

Richard J. F. (2004). Les activités mentales. Paris: Armand Colin.

Rönnlund, M., Lövdén, M., \& Lars-Göran, N. (2001). Adult age differences in Tower of Hanoi Performance: Influence from demographic and cognitive variables. Aging, Neuropsychology, and Cognition, 8(4), 269-283.

Trofatter, C., Kontra, C., Beilock, S., \& GoldinMeadow, S. (2014). Gesturing has a larger impact on problem-solving than action, even when action is accompanied by words. Language, Cognition and Neuroscience, 30(3), 251-260.

Welsh, M. C. (1991). Rule-Guided Behavior and Self-Monitoring on the Tower of Hanoi Disk-Transfer Task. Cognitive Development, 6(1), 59-76.

Welsh, M. C., Penington, B. F., \& Groisser, D. B. (1991). A normative 
developmental study of executive function: A window on prefrontal function in children. Developmental Neuropsychology, 7(2), 131-149.

Welsh, M. C., Satterlee-Cartmell, T., \& Stine, M. (1999). Towers of Hanoi and London: Contribution of Working Memory and Inhibition to Performance. Brain and Cognition, 41 (2), 231-242.

\section{Notes}

* Research article.

1 A trajectory was defined as the way of verbal and gestural successive explanations of participants generated to explain the "mental" movement that would lead them to solve the task or not. 